SunYer, Magí; Emili SAMPER (eds.): La llegenda. Estudis Catalans 9. Kassel: Edition Reichenberger, 20I9, $250 \mathrm{p}$.

\title{
La Ilegenda
}

Tomàs VIBOT RAILAKARI

Universitat de les Illes Balears, Palma

Els estudis etnopoètics reclamaven des de feia temps més base teòrica i cabal reflexiu per abordar la complexitat del concepte llegenda. Aquest llibre es va concebre per posar damunt la taula un debat sobre aquest terme, determinar-ne els límits, examinar-ne l'evolució i observar el rendiment que ha proporcionat en textos literaris significatius. Aquest treball és iniciativa del Grup de Recerca Identitats en la Literatura Catalana (GRILC) i compta amb la col-laboració del grup de recerca Literatura, Iconografia i Recepció de l'Antiguitat (LIRA), tots dos de la Universitat Rovira i Virgili. Es tracta d'un volum que acull tretze articles on s'aborda la llegenda des de perspectives diferents, ben necessàries per esbrossar un cap terminològic ple de confusions.

El llibre es troba dividit en dos grans blocs. El primer, titulat «Conceptes i límits», agrupa les contribucions que situen la llegenda en relació als gèneres amb què d'una o altra manera s'interacciona. Per aquest motiu, aporta gran quantitat d'elements per a la definició del gènere.

En el primer d'aquests articles, titulat «La llegenda, un dels grans gèneres del folklore narratiu», Carme Oriol reflexiona sobre el concepte llegenda i n'estudia els punts de contacte i les diferències que poden establir-se entre el mite i la llegenda, així com la descripció dels grans grups que en configuren l'espai conceptual. L'article, ple d'exemples procedents del folklore en llengua catalana, traça una panoràmica sobre l'espai que ocupa en el folklore a partir de les aportacions realitzades per alguns dels estudiosos que més hi han treballat. Així mateix, Oriol aprofundeix en les característiques de tres tipus de llegendes: la llegenda etiològica (les que «expliquen l'origen i el perquè del fenòmens remarcables de la natura que ens envolta [...] i fenòmens que s'observen al cel», p. I5-I6), la llegenda de creença (relats on personatges que tenen un poders sobrenaturals entre en contacte amb els humans) i la llegenda històrica (aquelles narracions sobre personatges històrics - cavallers, reis, bandolers, etc. - que protagonitzen episodis extraordinaris).

Jesús Carruesco, a l'article «La llegenda en el món grec», aborda aquesta difícil qüestió, atès que el que avui dia coneixem com a llegenda és un concepte purament medieval, relacionat inicialment amb les vides de sants. L'absència, per tant, a nivell etimològic d'una traducció evident de la llegenda moderna al grec antic, en dificulta la tasca però alhora no en nega la inexistència. Partint d'una triple classificació (etiològica, històrica i sobrenatural), l'autor repassa una bona partida de narracions de l'antiguitat grega i en troba prou rastres. Per exemple, dins el període més tardà, és a dir, l'hel-lenístic i l'imperial, es localitzen narracions que ben bé encaixen en dites categories. Així, a l'obra de Cal-límac (s. III $\mathrm{aC})$ s'hi poden advertir nombroses llegendes «que explicaven l'origen de diversos costums, rituals o fets històrics» (p. 27). Però sobretot serà Plutarc qui en presenti un nombre més significatiu i transcendent. Quant a llegendes històriques, Carruesco analitza la figura d'Alexandre el Gran, «al voltant del qual apareix ben aviat tot un seguit de relats llegendaris que configuren una tradició paral-lela a la 
de l'abundant producció historiogràfica sobre el personatge» (p. 28). Finalment, les llegendes sobrenaturals o de creença es poden localitzar en diversos autors, com per exemple a Flegó de Tral·les. La llegenda dins la Grècia arcaica i clàssica muda d'espai i en aquest període «se situa a la perifèria del mite, ocupant aquells espais que aquesta va deixant lliures en les fronteres amb els nous discursos, en especial a les fronteres entre el mite i la història i entre el mite i la literatura» (p. 3I). És a dir, la identificació es fa força més complicada, encara que és possible localitzar relats amb característiques pròpies de la llegenda.

Diana Gorostidi tracta les llegendes a la Roma arcaica en un documentadíssim article titulat «Llegendes de la Roma arcaica: entre història, literatura i folklore». De tots és ben sabut que l'hegemonia de la Roma arcaica sobre la resta dels pobles del Laci es va consolidar historiogràficament en un sèrie de personatges de caire llegendari i de fets extraordinaris que van forjar el caràcter i el tarannà romà. Tal com afirma l'autora, en la formació d'aquest corpus de referents «van tenir un paper fonamental els escriptors d'època històrica que van, en certa manera, contribuir a la fossilització d'un cànon de figures i gestes heroiques que la tradició [...] havia anant creant i desenvolupant en la configuració del passat més remot de Roma» (p. 4I-42). Tot i que la diferenciació entre poetes i historiadors en la Roma posterior era prou clara, els fets de l'antiguitat romana eren tractats amb distància i també respecte, i d'aquí que la cultura popular en begués.

Magí Sunyer aborda la caracterització de la llegenda històrica dins el romanticisme català. Aquest tipus de relat es troba més que certificat en aquest període pels dos grans poemes narratius de Jacint Verdaguer (L'Atlàntida i Canigó), però també el localitzem en altres autors (Pau Piferrer, Manuel Milà i Fontanals, Víctor Balaguer, etc.). Per a Sunyer, dins el Romanticisme «la substitució dels mites clàssics per les llegendes no es va produir només com a conseqüència d'una moda sinó també per un canvi de funcions» (p. 69). Serà quan la mateixa naturalesa de l'home romàntic, qui permanentment viu entre el desassossec i la nostàlgia dels orígens, buscarà una connexió amb el passat medieval «que va acabar formant una nova constel-lació mítica en què van participar la literatura oral i les històries, antigues o medievals, que se suposava que la tradició també transmetia» (p. 69). És a dir, l'autor apunta com els escriptors romàntics projecten una gran devoció per l'acte folklòric com una connexió amb un orígens col-lectius que ells consideren lligats a la transmissió de les llegendes. En aquest sentit, val la pena recordar com Milà i Fontanals avantposava les narracions folklòriques a la ciència contemporània com a font de coneixement. En aquest paper de revifament de les llegendes com a element nuclear de la identitat i del tarannà nacional, hi té un fort paper el naixement de l'excursionisme i també d'una nova concepció de la història, on per als romàntics catalans «la llegenda ajudava a omplir els buits que la història deixava sense explicació o sense narració» (p. 64).

En darrer article del primer apartat, Alfons Gregori aborda el tema del lligam del fantàstic amb la llegenda en un interessant article titulat «L'ambigüitat de la creença: la llegenda i el fantàstic a la llum de les teories contemporànies de la literatura i el folklore». Segons les teories del folklore avui establertes, la llegenda es caracteritza per inserir-se en el sistema de creences de la comunitat que transmet els fets extraordinaris expressats als relats d'aquest gènere i, a través de referències geogràfiques o històriques, és susceptible de ser presa com a certa. Quan en les llegendes del passat preindustrial apareixia un ésser o un fet sobrenatural, entra- 
va dins l'àrea d'allò meravellós. Però una de les preguntes que es fa Gregori és si aquests mateixos paradigmes es poden aplicar en la llegenda contemporània. D'aquí que se'n plantegi diverses preguntes: «aquelles que se segueixen explicant en el folklore contemporani, continuen formant part d'un meravellós "transformat", igual que en l'àmbit de la literatura passava amb el surrealisme o el realisme màgic? O bé podrien entrar a forma part del fantàstic per l'ús de figuracions i motiu habitual en aquesta modalitat narrativa i per la seva ambientació derivada sovint del gòtic?» (p. 80). Aquestes i altres qüestions porten l'autor a reflexionar sobre les aportacions de diversos folkloristes sobre aquesta qüestió, per arribar a la conclusió que un aspecte de coincidència notable entre allò fantàstic i el llegendari de les societats postindustrials «consisteix en la voluntat que semblen expressar de transgredir el paradigma creencial instal-lant en el marc institucional: tant el laïcisme empirista promogut pels poders civils i el seu entorn mediàtic com les diferents variants del monoteisme en les institucions religioses» (p. 85).

El segon apartat del llibre, titulat «Llegenda i literatura», l'enceta Joana Zaragoza Gras amb l'article «Aquil-les: una vida breu i una fama eterna», on es reflexiona si aquest personatge de la Ilíada es tracta d'un heroi de llegenda, d'un mite o d'un personatge èpic. La tasca evidentment no resulta gens fàcil, atès que la diferència entre mite i llegenda dins la literatura grega antiga és molt líquida, fet que també passa en els textos que fan referència a la història de Grècia, la qual beu tant de la realitat com de la ficció. Després d'una anàlisi força ben documentada, l'autora arriba a la conclusió que es tracta d'un heroi de llegenda, ja que es basa sobre una guerra que realment va existir — ateses les nombroses restes arqueològiques-, però la narració es troba acompanyada d'una sèrie d'elements «imaginaris amb el desig [...] que sigui cregut per part de l'auditori» (p. 97). Però, de més a més, Aquil.les també es trobaria dins la categoria de personatge de llegenda, ja que en la seva construcció es troba farcit de mites que han quedat com a paradigma -o símbol- de l'heroi guerrer «que va optar per una vida breu i una fama eterna» (p. Ioo).

Emili Samper se centra en la figura del folklorista Francesc de Sales Maspons i Labrós (I840-I9OI) i, més concretament, en l'obra Tradicions del Vallés, un recull de sis llegendes acompanyades de notes comparatives que suposa un fet clau per a l'estudi de la llegenda folklòrica a Catalunya, donat que se'n pot considerar el primer. Cal situar el treball de Maspons dins el context històric en què es va fer, ja que es tracta d'un recull procedent de la tradició oral, encara que recreades per l'estil que el romanticisme imposava en aquells moments. Ara bé, tal com afirma Samper «el valor del recull, però, no es troba només en aquests sis relats presentats per Maspons sinó en les notes que el folklorista vallesà inclou i en les quals aporta informació valuosa sobre aquestes mateixes llegendes i les versions que es poden localitzar en altres indrets o cultures, diferents de la catalana, en un exercici comparatiu que mostra la coneixença que sobre el tema tenia qui fou una figura clau en l'estudi del folklore a Catalunya» (p. II9).

Margarida Aritzeta se centra en l'obra de Narcís Oller i la petja de les llegendes en el seu cabal literari. Amb l'article «Narcís Oller, llegendes, mites nacionals i mites literaris», l'autora repassa el conjunt de les seves primeres obres per arribar a la conclusió que els universos ficcionals d'Oller es nodreixen de referents reals que li serveixen per bastir trames imaginades, encara que també s'alimenten de mites literaris, llegendes i mites nacionals. En aquestes obres apareixen relats llegenda- 
ris perfectament identificats, com ara les bruixes del mas de Moragues, la llegenda de sant Eloi, la llegenda de l'origen d'Alcover o les guineus de Vallclara. Tal com afirma Aritzeta, l'anàlisi de l'onomàstica de les primeres novel-les «ens fa veure la complexitat de la tasca de Narcís Oller i la seva contribució conscient a l'hora de posar les bases d'una literatura nacional que es nodrís d'un imaginari llegendari i simbòlic proper i alhora d'inserir aquest imaginari en el marc de la literatura moderna de finals del segle XIX» (p. I33).

«Llegenda i festa. Narcís Oler i Josep Aladern» és el títol del treball d'Albert Oliva, que reflexiona sobre els ponts, les imbricacions i els espais comuns entre aquestes dues manifestacions culturals. Els dos conceptes tenen com a punt de partida la interacció humana i la seva relació amb el medi més immediat. Aleshores, llegenda i festa són conceptes assimilats i conformen part cabdal del patrimoni immaterial d'un col-lectiu. Partint d'aquests postulats, l'autor analitza la novel-la Vilaniu de Narcís Oller i l'assaig Costums típicas de la ciutat de Valls de Josep Aladern per arribar a la conclusió que a través d'ambdues obres s'estableix una interrelació oberta entre la literatura i el folklore i, en conseqüència, la descripció literària de sengles textos «esdevé el millor punt de partida per establir una connexió entre l'espai físic literari i un segui d'indrets, elements i localitzacions en què hi conviu un corpus extens de llegendes, contalles i relats orals» (p. I47).

La llegenda del comte Arnau és una de les més tractades al llarg de la història de la literatura catalana. Jordina Gort Oliver, al seu article «La llegenda del comte Arnau vista per Frederic Soler», se centra en l'adaptació teatral que en feu aquest autor amb el títol Lo comte l'Arnau. En aquest article, Gort descriu el tractament que fa Serafí Pitarra sobre la llegenda, de quina manera l'aborda, quina intenció i quina funció té aquesta llegenda durant la Renaixença. Així mateix, hi analitza les influències i les fonts que fa servir l'autor per crear la seva versió, així com la recepció i el sentit dins el cabal literari de Frederic Soler. Tot i que per a Gort aquest drama no és gaire rellevant (més aviat mediocre si atenem a la trajectòria de Frederic Soler), sí que resulta «una adaptació curiosa de la llegenda del comte Arnau» (p. r69), ja que «inventa tota una trama plena d'intrigues, misteris, traïcions i venjances entre diversos personatges que, en excés, podien arribar a cansar» (p. I69). És clar que, en el cas de Soler, el pretext del comte Arnau prové de la idea bàsica de recuperar les llegendes perquè això significava la revitalització de l'ànima del poble (Volkgeist), tant en voga durant el romanticisme.

Montserrat Corretger, amb l'article «Relat llegendari fundacional i llegenda: la prosa narrativa de Carner, López-Picó i Maseras el I922", analitza tres obres narratives d'aquests autors (La creació d'Eva i altres contes, Lleures barcelonins i Setze contes) amb la finalitat de concloure comparativament la funció que de la llegenda — juntament amb altres gèneres populars de tradició oral- compleix en aquestes obres en relació amb el projecte noucentista. Per a l'autora, «si els dos primers marquen idees i funcions i concreten el model narratiu noucentista, el tercer se'n fa seguidor ultrat sense aconseguir assimilar aquest model» (p. I7I).

«Folklore i llegenda en el teatre de Ventura Gassol: La mort de l'os» és un treball de Montserrat Palau on s'analitza aquest poema coreogràfic perquè Gassol hi fa ús del llegendari com a forma de dotar el teatre català d'una tradició que en mancava. El mateix Gassol, a la seva conferència «El nacionalisme en el teatre», afirmava que la llegenda, a més dels valors d'evocació que pot tenir la història, de religió o d'esdeveniments extraordinaris que les puguin haver motivat, té la fun- 
ció d'evocar-nos els nostres personatges llegendaris i de mica en mica anar-nos-hi fusionant. Aquests postulats els posarà també en pràctica en la seva obra dramàtica. Serà, però, a La mort de l'os on a més de la llegenda l'autor hi crearà un tot wagnerià on es fusionen elements com el simbolisme, el folklore, la música, la poesia, la religió i la nació. Tal com afirma Palau, «Gassol [...] creia en el teatre com un art total format per l'expressivitat de les llegendes dramatitzades tot combinant-les amb diverses arts, per reflectir la idiosincràsia nacional» (p. 204).

Finalment, Joan R. Veny-Mesquida, amb l'article titulat «De la "llegenda" de la reina Esther a la Primera història espriuana», analitza algunes de les estratègies literàries de què se serveix Espriu per convertir la contarella, la llegenda, l'anècdota oriental, l'immortal apòleg del llibre d'Esther bíblic en la seva Primera història d'Esther. Veny-Mesquida arriba a la conclusió que la versió que Espriu fa d'aquesta «semillegendària narració bíblica» respecta en termes generals l'argument de la llegenda "però aconsegueix de trencar totes les expectatives del lector» (p. 219). A diferència del que farà amb Laia, l'escriptor colomenc en farà una «reinterpretació subversiva de la llegenda» (p. 219), però amb una finalitat comuna: la d'incorporar als textos de partida Sinera.

El volum La llegenda, concebut com un espai de reflexió coral per tractar el camp terminològic d'aquest concepte, resulta avui una fita cabdal dins la bibliografia de la teoria del folklore. No sols aborda el concepte des de l'arrel, sinó també des de les mateixes fronteres, per la qual cosa aquesta varietat d'enfocaments defuig la simplificació i enforteix el discurs. Un treball que suma no sols continguts, sinó que obre les portes a l'enriquiment del debat. 